Results A total of 399 practice or game sessions were observed over 2 sport seasons (62\% in intervention schools).A greater proportion of coaches in the intervention group provided alignment cues to correct improper technique compared to coaches in the control group [difference $=0.04$ (95\% CI: $0.01,0.07, \mathrm{p}=0.006]$. There was a similar proportion of coaches in the intervention and control groups who provided exercise instructions [difference $=0.01$ (95\% CI: $-0.02,0.04$ ), $\mathrm{p}=0.44]$.

Conclusions One barrier to adoption of injury prevention programs may be the coach's lack of knowledge on how to implement a warm-up routine that is effective at reducing ACL injuries. A coach education workshop may lead to actual behavior change in practice.

\section{THE RELATIONSHIP BETWEEN THE INJURIES IN ELEMENTARY PE AND THE STAGES OF TEACHER PROFESSIONAL DEVELOPMENT}

Yuki Nakamura. Hokuriku university, Kanazawa, Japan

\subsection{6/bjsports-2021-IOC.331}

Background In Japan, the ministry has emphasized that safety management is important for PE instructions.

Objective The purpose of this study is to clarify the relationship between the injuries in elementary PE and the stages of teacher professional development.

Design The method of this study is to collect the number of injuries in elementary $\mathrm{PE}$ in each professional development stage by the record of Japanese school health room. These collected data are classified into three types of injuries: Open wound, Closed wound, Other wound. The survey was conducted in 2014.

Setting Elementary school of physical education.

Patients (or Participants) The subjects were nine Japanese elementary schools that received research cooperation. The number of participants was 54 teachers (20 novice teachers, 15 experienced teachers, 19 expert teachers).

Interventions (or Assessment of Risk Factors) The independent variables were the three stages of teacher professional development.

Results 1) When focusing on the total number of injuries, there were no significant differences among three professional development stages $(p<.05)$. 2) When focusing on the total number of injuries, there were no significant differences between male novice teachers, female novice teachers, male experienced teachers, female experienced teachers, male expert teachers and female expert teachers $(\mathrm{p}<.05)$. When focusing on the proportion of three types of injuries, there were significant differences among three professional development stages $(\mathrm{p}<.05)$. Closed wound were more common in the experienced teacher stage and less common in the expert teacher stage. On the other hand, Open wound was more common in the Expert teacher stage and less common with Novice teachers and Experienced teachers.

Conclusions In particular, it is suggested that the quality of injury changes from serious injuries to minor injuries between Experienced teachers and Expert teachers. That is, it implicates that professional development of safety management in $\mathrm{PE}$ is different between Experienced teacher and Expert teacher.

\section{5 MOVE HEALTHY-THE IDENTIFICATION OF CURRENT NATIONAL INJURY PREVENTION PROGRAMS AND BELIEFS OF COACHES AND YOUTH REGARDING INJURY PREVENTION IN 6 EUROPEAN COUNTRIES}

${ }^{1}$ Joske Nauta, ${ }^{2}$ Johan de Jong, ${ }^{3}$ Kristine De Martelaer, ${ }^{4}$ Paul Dragos, ${ }^{2}$ Remo Mombarg, ${ }^{5}$ Danielle Nørager Johansen, ${ }^{5}$ Thomas Skovgaard, ${ }^{4}$ Paul Szabo-Alexi, ${ }^{1}$ Evert Verhagen,

${ }^{2,6}$ Anne Benjaminse. ${ }^{1}$ Amsterdam UMC, Amsterdam, Netherlands; ${ }^{2}$ Hanze University of Applied Sciences, Groningen, Netherlands; ${ }^{3}$ Vrije Universiteit Brussel, Brussel, Belgium; ${ }^{4}$ University of Oradea, Oradea, Romania; ${ }^{5}$ University of Southern Denmark, Odense, Denmark; ${ }^{6}$ University Medical Center Groningen, Groningen, Netherlands

\subsection{6/bjsports-2021-IOC.332}

Background Despite the importance of sports injury prevention in youth, no broad scale approaches that work in real-life situations with significant positive effects exist. Main reasons for this are poor uptake and maintenance of current sports injury prevention exercises.

Objective In order to improve uptake of sports injury prevention routines, this project set out to: 1 . identify the specifics of current injury prevention programs within 6 European countries, and 2: to establish wishes and needs regarding injury prevention of the end-users (sport coaches, physical educators and youth) within 6 European countries.

Design Semi-structured interviews and focus group sessions. Setting Youth sports teams and physical education (PE) classes. Patients (or Participants) Interviews and focus group sessions were performed within 6 participating countries (Belgium, Denmark, Lithuania, Romania, The Netherlands, United Kingdom). National stakeholders were interviewed to identify injury prevention programs. The program owners of the identified programs were then individually interviewed. The focus group sessions were organized with youth basketball and soccer players and PE pupils. Separate focus group sessions were organized for basketball/soccer coaches and physical educators.

Interventions (or Assessment of Risk Factors) This qualitative study provided input for the development of a freely available ICT based platform with video material of routines designed to prevent sports injuries in youth.

Main Outcome Measurements Overview of country specific results of interviews and focus groups.

Results This study will describe the current availability of national injury prevention programs within 6 European countries. The results of the focus group sessions will establish the differences in beliefs regarding injury prevention in 6 European countries regarding injury prevention.

Conclusions In the coming year, the Move Healthy project will use the qualitative results of this study to develop a freely available ICT based platform with video material of routines developed to prevent sports injuries in youth.

\section{SHINING A LIGHT ON INJURY STATUS: DEVELOPING AN EFFECTIVE METHOD TO MONITOR PLAYER AVAILABILITY AND IMPROVE COMMUNICATION BETWEEN COACHES AND MEDICAL STAFF}

\footnotetext{
${ }^{1,2}$ Ciarán Purcell, ${ }^{1,2}$ Catherine Blake, ${ }^{1,2}$ Ulrik McCarthy Persson, ${ }^{1,2}$ Sinead McMahon,

${ }^{1,2}$ Caitriona Cunningham, ${ }^{1,2}$ Frank Kenny. ' UCD Physiotherapy Hub, Dublin, Ireland; ${ }^{2}$ UCD School of Public Health, Physiotherapy and Sport Science, Dublin, Ireland
}

10.1136/bjsports-2021-IOC.333 